\title{
AVALIAÇÃO SENSORIAL DO PÃO DE FORMA ENRIQUECIDO COM FARINHA RESIDUAL DE ALGAROBA (Prosopis juliflora (Sw.) DC)
}

\author{
C. G. DA SILVA ${ }^{1}$, M. E. R. M. CAVAlCANTI MATA ${ }^{2}$, M. B. MUNIZ ${ }^{3}$, C. G \\ RODRIGUES $^{3}$, F. C. DOS SANTOS LIMA ${ }^{4}$ e C. Q. GOUVEIA ${ }^{5}$ \\ ${ }^{1}$ Universidade Federal da Paraíba, Departamento de Engenharia Química \\ ${ }^{2}$ Universidade Federal de Campina Grande, Departamento de Engenharia Agrícola \\ ${ }^{3}$ Universidade Federal de Campina Grande, Departamento de Engenharia Química \\ ${ }^{4}$ Universidade Federal de Campina Grande, Departamento de Engenharia Química \\ ${ }^{5}$ Engenheira de Alimentos e Especialista em Engenharia de Segurança do Trabalho \\ E-mail para contato: algarobeira@gmail.com
}

\begin{abstract}
RESUMO - O pão de forma convencional é um produto que apresenta em sua composição excelente nível de aceitação no mercado, embora o valor agregado do produto indique a necessidade de avaliar o efeito da adição de outras matériasprimas como alternativas para redução de custos na sua elaboração. Para se avaliar a qualidade de um produto deve-se levar em conta as propriedades sensoriais aceitáveis como essenciais no momento de sua venda e consumo. O presente trabalho teve como objetivo avaliar o perfil sensorial de pão de forma enriquecido com a substituição parcial 5, 10 e $15 \%$ da farinha de trigo pela farinha de algaroba denominados PF1- pão de forma 1, PF2 - pão de forma 2 e PF3 - pão de forma 3 respectivamente. A metodologia aplicada foi o teste efetivo de aceitação, um teste que possibilita transformar dados subjetivos em objetivos e fornecer informações importantes sobre o quanto as pessoas gostam ou não de um determinado produto. O pão foi avaliado segundo os atributos: sabor e aroma utilizando-se da escala hedônica estruturada de nove pontos, variando do gostei muitíssimo (9) ao desgostei muitíssimo (1), Com a participação de 59 provadores não treinados. Estatisticamente para o atributo aroma o nível de aceitação para PF1 e PF2 não diferem em nível de 5\% de probabilidade. Concluir-se que o nível de aceitação do pão de forma em relação aos atributos aroma e sabor, depende da concentração de farinha residual de algaroba adicionada na sua formulação.
\end{abstract}

\section{INTRODUÇÃO}

A importância socioeconômica da algarobeira (Prosopis juliflora) para a região Nordeste, deve-se ao fato de ser uma leguminosa de rápido crescimento, elevada resistência a seca, comprovado potencial energético e estar inteiramente associada a inúmeras aplicações e usos no meio rural. As propriedades químicas e nutricionais dos seus frutos, favorecem a aplicação e o aproveitamento integral destes frutos, no desenvolvimento de diversos processos de inovação tecnológica. A transformação das suas vagens em produtos processados gera resíduos 
que se descartados no meio ambiente desperdiça uma fonte importante de nutriente e podem impactar.

O pão de forma convencional é um produto que apresenta excelente nível de aceitação no mercado, embora o valor agregado do produto o encareça. $\mathrm{O}$ custo elevado do seu principal componente, a farinha de trigo, indica a necessidade de testar outras alternativas para redução de custos em suas formulações. Desta forma, a análise, o tratamento e a transformação dos resíduos sólidos derivados de produtos fermento destilados, contribuirá para sua aplicação na obtenção de outros produtos de reconhecido valor comercial, redução dos custos de produção e agregando valor à cultura da algarobeira valorizando a sua cadeia produtiva e gerando oportunidade de emprego e renda para a população.

Embora, alguns países da América Latina já se destaquem na exploração das vagens da algarobeira para fins agroindustriais, o Brasil ainda não atingiu esse nível de conhecimento e desperdiça grande quantidade destes recursos no campo. Matérias-primas tais como, melado, farinhas, géis, gomas dentre outras, são produzidas e exportadas para diversos países e utilizadas como espessantes, estabilizantes, conservantes, expectorantes, deslizantes e uma infinidades de alimentos importantes em função das suas propriedades nutri funcional, energética e ou tecnológicas. Produtos como, bolos, biscoitos, pães, balas, sorvetes, refrigerantes, coquetéis, licores, chocolates dentre outros são comuns em diversos países (FIGUEIREDO, 2004).

Portanto, o objetivo desse trabalho foi avaliar sensorialmente o nível de aceitação da adição de diferentes concentrações da farinha residual de algaroba em pão de forma enriquecido com a substituição parcial 5, 10 e 15\% da farinha de trigo pela farinha de algaroba.

\section{MATERIAL E MÉTODOS}

Foi desenvolvido no Campus I Universidade Federal de Campina Grande e contou com o apoio técnico do Instituto Federal de Educação, Ciência e Tecnologia do Campus de Belo Jardim, PE.

\subsection{Matéria-prima}

A matéria-prima utilizado no processo foi farinha residual de algaroba obtida pela secagem, moagem e peneiramento da fração sólida (resíduo) proveniente do processo de obtenção da aguardente de algaroba. 


\subsection{Produção do pão de forma}

Para a obtenção das amostras, foram elaborados de pão de forma enriquecido com a substituição parcial de 5, 10 e $15 \%$ da farinha de trigo pela farinha de algaroba com granulometria de 60 mesh $(0,250 \mathrm{~mm})$ e denominados PF1 - pão de forma 1, PF2 - pão de forma 2 e PF3 - pão de forma 3 respectivamente, o que corresponde a 95, 90 e $85 \%$ de farinha de trigo comercial no balanço mássico, conforme Tabela 1.

Tabela 1 - Balanço mássico para os pães PF1, PF2 e PF3 com farinha de algaroba

\begin{tabular}{ccccccc}
\hline F.TRIGO & ÁGUA & AÇÚCAR & F.ALGAROBA & G. HIDROGENADA & SAL & FERMENTO \\
\hline $95 \%$ & $60 \%$ & $6 \%$ & $5 \%$ & $4 \%$ & $1,8 \%$ & $1 \%$ \\
$90 \%$ & $60 \%$ & $6 \%$ & $10 \%$ & $4 \%$ & $1,8 \%$ & $1 \%$ \\
$85 \%$ & $60 \%$ & $6 \%$ & $15 \%$ & $4 \%$ & $1,8 \%$ & $1 \%$ \\
\hline
\end{tabular}

\subsection{Descrição do processo de obtenção}

Farinha: A farinha obtida por secagem e moagem do resíduo, foi submetida a um processo de tamisação em peneira de marca GRANUTEST, de abertura 0,250 mm (60 mesh) da série de Tyler em substituição ao trigo aplicando-se o mesmo método adotado por Dias e Leonel (2006).

Pesagem: A pesagem dos ingredientes definiu quantitativamente os percentuais de farinha de algaroba, farinha de trigo e outras substâncias a serem adicionados ao produto. Os percentuais testados foram baseados em processos convencionais já existentes para o pão de forma e em testes preliminares de panificação realizados em laboratório.

Mistura: A mistura foi realizada manualmente e os ingredientes foram adicionados na seguinte proporção e ordem: misturou-se a farinha de trigo com a farinha de algaroba, açúcar, gordura vegetal hidrogenada e água; a adição do sal foi feita por último para evitar ser efeito inibidor sobre o fermento biológico.

Hidratação: A água gelada foi adicionada em quantidade suficiente para homogeneizar e dar consistência. A hidratação da massa foi lenta e em pequena quantidade, amassando-se sempre a massa, com cuidado para não umedecê-la demais.

Amassamento: Para o amassamento, a mistura foi acondicionada na masseira até formar uma massa elástica e brilhante, com adição de pequenas quantidades de água e em seguida colocada em cilindro até total consistência. 
Salga: O processo de salga foi realizado lentamente durante a mistura da massa, após a adição de todos os ingredientes.

Modelagem: Depois de hidratada, a massa passou pelo processo de modelagem, foi salgada e modelada, até tingir consistência branda e perder a elasticidade, fato observado quando, ao se puxar com o rodo, a massa tendia a permanecer expandida na bancada, não oferecendo resistência ao rodo.

Fermentação: Na fase conhecida como fermentação, fase de crescimento ou de repouso da massa, cada amostra foi modelada manualmente e colocada em formas de tamanho padrão para fermentar em câmara de fermentação em temperatura média de $35^{\circ} \mathrm{C}$, por aproximadamente uma hora, até atingir o crescimento ideal, volume e firmeza para ser assado. O crescimento foi atingido quando o pão ocupou toda a forma e o processo de fermentação foi interrompido ao se verificar a paralisação do aumento do volume.

Cozimento: No cozimento, a massa modelada e fermentada foi imediatamente levada ao forno elétrico turbo a gás, de Marca: TOLLEDO, com capacidade para 200 pães, aquecida a temperatura de $180^{\circ} \mathrm{C}$, durante sete minutos, $\mathrm{O}$ pão foi retirado do forno quando a crosta apresentou coloração amarela intensa e brilhante.

Análise sensorial: Para a avaliação do nível de aceitação sensorial dos pães de forma PF1, PF2 e PF3 quanto aos atributos relacionados ao sabor e ao aroma, foram analisadas três amostras por 59 provadores não treinados da Escola Agrotécnica Federal de Belo Jardim - PE. Para isso, foi realizado um teste de aceitação por escala hedônica com nove denominações que vão desde o gostei muitíssimo até desgostei muitíssimo.

As amostras foram apresentadas codificadas com algarismos de três dígitos, cada provador recebeu três amostras e avaliou separadamente, de acordo com a metodologia aplicada no teste efetivo, em que se verifica os efeitos sensoriais perceptíveis de cada amostra e, podese avaliar um grande número de consumidores a respeito da aceitação de um determinado produto.

Análise estatística: Os dados experimentais obtidos na análise sensorial foram analisados estatisticamente com o uso do programa computacional ASSISTAT versão 7.5 beta SILVA (2009). O delineamento experimental foi o inteiramente casualizado (DCC) cujos resultados foram submetidos a análise de variância. A comparação entre as médias dos dados foi feita através do teste de Tukey a 5\% de probabilidade. 


\section{RESULTADOS E DISCUSSÃO}

\subsection{Resultados}

As Figuras 1, 2 e 3 apresentam os valores atribuídos para os atributos de sabor e aroma percebidos pelos provadores não treinados para o pão de forma enriquecido com 5, 10 e $15 \%$ da farinha do resíduo de algaroba.

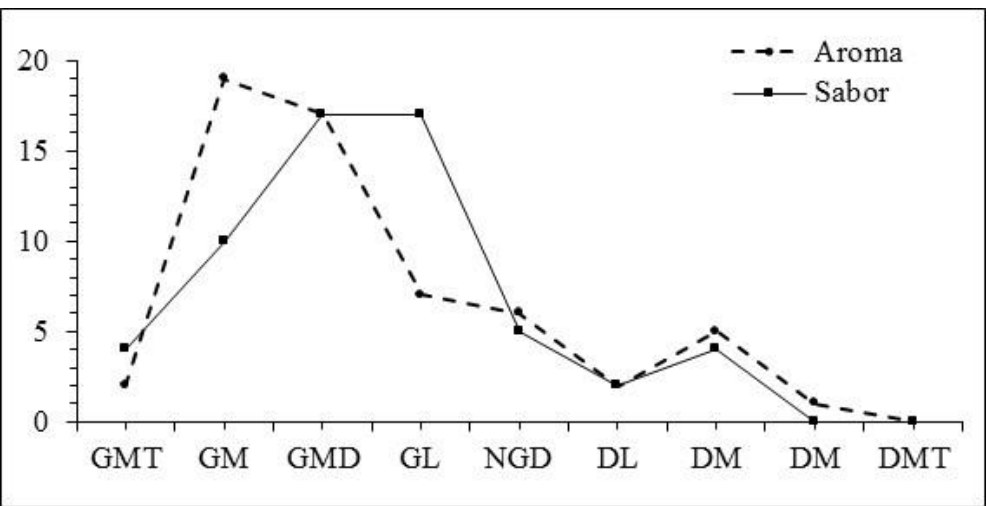

Figura 1 - Valores atribuídos ao pão de forma processado com concentração de farinha de resíduo de algaroba de $5 \%$.

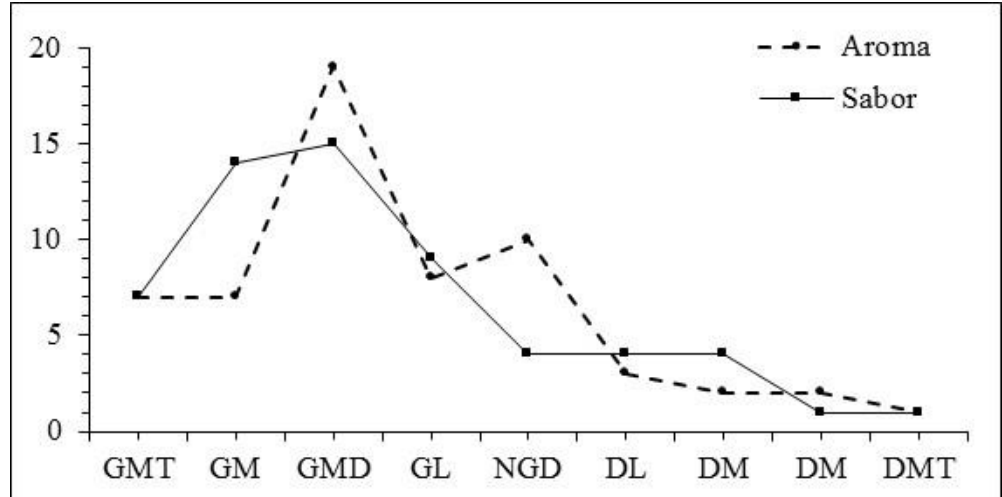

Figura 2 - Valores atribuídos ao pão de forma processado com concentração de farinha de resíduo de algaroba de $10 \%$.

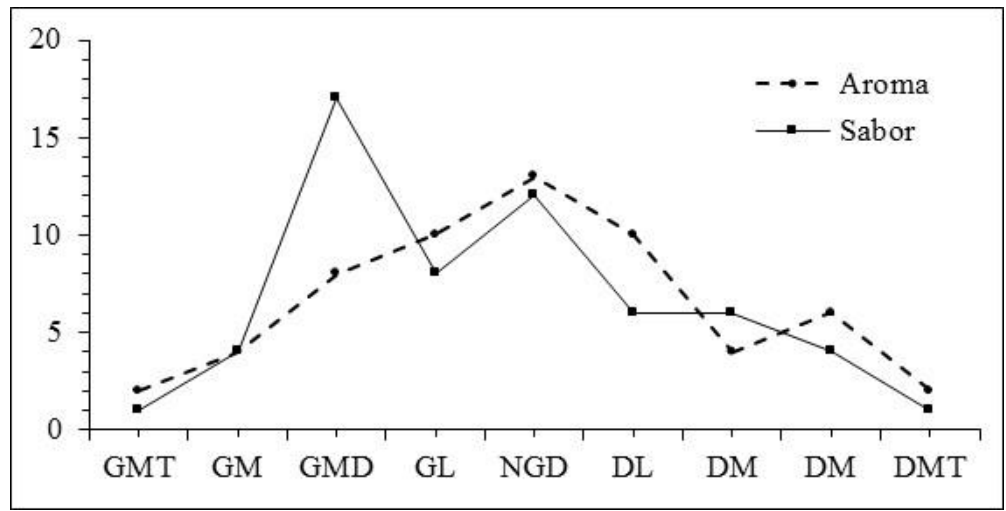


Figura 3 - Valores atribuídos ao pão de forma processado com concentração de farinha de resíduo de algaroba de $15 \%$.

\subsection{Discussão}

Observando-se os três gráficos simultaneamente, observa-se para o sabor, a preferência foi para o pão produzido com $10 \%$ e, para o aroma, a maior aceitação foi para o pão, com percentual de $15 \%$ de farinha de resíduo de algaroba.

A análise estatística: Na Tabelas 2 e 3 estão expostos os resultados da análise de variância e a comparação entre as médias para a análise sensorial de sabor e aroma do pão de forma processado com farinha de resíduo de algaroba nas concentrações de 5, 10 e 15\%.

Tabela 2 - Resultados da análise de variância do atributo sabor

\begin{tabular}{ccccc}
\hline FONTE DE & GRAU DE & SOMA DOS & QUADRADO & \multirow{2}{*}{ F } \\
VARIAÇÃO & LIBERDADE & QUADRADOS & MÉDIO & 11,1713 \\
Tratamentos & 2 & 75,90805 & 37,95402 & \\
Resíduo & 171 & 580,96552 & 3,39746 & \\
& 173 & 656,87356 & & \\
\hline
\end{tabular}

Tabela 3 - Resultados da análise de variância do atributo aroma

\begin{tabular}{ccccc}
\hline FONTE DE & GRAU DE & SOMA DOS & QUADRADO & F \\
VARIAÇÃO & LIBERDADE & QUADRADOS & MÉDIA & \\
\hline Tratamentos & 2 & 51,90805 & 25,95402 & $8,5442^{* * *}$ \\
Resíduos & 172 & 519,43103 & 3,03761 & \\
Total & 173 & 571,33908 & & \\
\hline
\end{tabular}

Nas Tabela 4 e 5 estão expostos os resultado da análise estatística de comparação dos atributos sabor e aroma em relação a concentração da farinha de resíduo da algaroba nas concentrações de 5, 10 e $15 \%$ utilizada no pão.

Observa-se que não existe diferença significativa entre os tratamentos com 5 e $10 \%$ da farinha; para o pão de forma produzido com $15 \%$ da farinha de algaroba em relação ao pão produzido com 5 e $10 \%$ da farinha na sua composição, ocorreu diferença significativa de $1 \%$.

Tabela 4 - Análise de comparação entre as médias para o atributo atributo sabor TRATAMENTOS SABOR 
Tabela 5 - Análise de comparação entre as médias para o atributo aroma

TRATAMENTOS AROMA

$5 \%$ farinha de algaroba

Verifica-se estatisticamente que o aroma do pão de forma produzido com 5 e $10 \%$ também não difere significativamente a $1 \%$ de probabilidade, enquanto que para um percentual de $15 \%$, observou-se uma diferença significativa em relação às concentrações anteriores.

\section{CONCLUSÃO}

Portanto, concluiu-se que os pães com melhores níveis de aceitação entre os julgadores foram aqueles elaborados com níveis de substituição de $10 \%$ de farinha de resíduo de algaroba e que os níveis de substituição de 5 e $15 \%$, embora tenham sido escolhidos pelo aroma, não se apresentaram adequados para a elaboração do pão de forma, haja visto que seu sabor é afetado negativamente, provavelmente em função da adstringência conferida pelos teores de taninos contidos na farinha de algaroba.

\section{REFERÊNCIAS}

DIAS, L. T.; LEONEL, M. Caracterização físico-química de farinhas de mandioca de diferentes localidades do Brasil. Cienc. Agrotec. Lavras, v. 30, n. 4, p. 692 - 700, jul./ago., 2006.

FIGUEIREDO, A.A.; ASCHERI, J.L.R.; CARVALHO, C.W. Produção de expandidos à base de farinha mista de algaroba e arroz e de algaroba e milho. In: Congresso Brasileiro de Ciência e Tecnologia de Alimentos - Estratégia para o Desenvolvimento, 2004, Recife. Anais...Recife: SBCTA, 2010. CD-Rom.

SILVA, C.G. Desenvolvimento de um sistema micro-industrial para obtenção de aguardente bidestilada de algaroba (Prosopis juliflora (Sw) DC). 2002. 108f. Dissertação (Mestrado em Engenharia Agrícola) - Departamento de Engenharia Agrícola, Universidade Federal de Campina Grande, Campina Grande.

SILVA, C. G.. Otimização da fabricação da aguardente de algaroba e aproveitamento dos resíduos sólidos em produtos alimentares. Clóvis Gouveia da Silva. 235 p. Tese (Doutorado em Engenharia de Processos). Departamento de Engenharia Agrícola. Campina Grande, 2009. 
SILVA, F. S. A. Assistat Versão 7.5 Beta. Campina Grande: UAEG, CTRN, UFCG. 2008. 